\title{
Importance of sustainable operations in food loss: evidence from the Belgian food processing industry
}

\author{
Manoj Dora ${ }^{1} \cdot$ Joshua Wesana ${ }^{2} \cdot$ Xavier Gellynck ${ }^{2} \cdot$ Nitin Seth $^{3} \cdot$ Bidit Dey $^{1}$. \\ Hans De Steur ${ }^{2}$
}

Published online: 17 January 2019

(c) The Author(s) 2019

\begin{abstract}
There are numerous studies on food loss on the demand side examining consumer behavior towards food choice and food waste generation at the household level. In this paper, we target food loss on the supply side, with a focus on the industrial food processing environment. More specifically, we map food loss in each processing stage, that is sustainable operations. Primary data were conducted through a survey (complemented with observations and documentary analysis) in 47 food processing companies in Belgium to identify hotspots and quantify food loss. The findings show that processing is by far the most important food loss hotspot. While transportation, changeover, interrupted production, human errors and product effects at this stage often lead to substantial or excessive losses, causes of food loss during packaging and before or after production have a smaller impact. At subsector level, however, there are substantial differences with respect to the most important causes. The originality of this research can be evaluated in three ways: one, identifying hotspots of food loss in the industrial processing environment; two, measuring the magnitude of losses across different product categories and causes and three, how sustainable operations plays a significant role in food loss prevention.
\end{abstract}

Manoj Dora

manoj.dora@brunel.ac.uk

Joshua Wesana

Joshua.wesana@ugent.be

Xavier Gellynck

Xavier.gellynck@ugent.be

Nitin Seth

nitinseth@iift.edu

Bidit Dey

bidit.dey@brunel.ac.uk

Hans De Steur

hans.desteur@ugent.be

1 Brunel Business School, Brunel University London, London, UK

2 Department of Agricultural Economics, Ghent University, Ghent, Belgium

3 Indian Institute of Foreign Trade, Delhi, India 
Keywords Food loss $\cdot$ Sustainable operations $\cdot$ Hotspots $\cdot$ Food processing companies

\section{Introduction}

Today, global efforts to fight hunger do not necessarily aim to increase world food production, but increasingly target the reduction of food losses and waste in both developing and developed countries (e.g. the FAO's Safe Food Initiative). Hence, food loss, i.e. the decrease in edible food mass along the supply chain (from production, postharvest, processing, and distribution to human consumption) (Aulakh and Regmi 2013; Segrè et al. 2014; Ivert et al. 2015), has never been more in the spotlight, at policy, industry and research level. Given its devastating economic, environmental and social impacts (Parfitt et al. 2010; Kummu et al. 2012; Rutten and Mhlanga 2015), food loss is currently considered to be one of the major bottlenecks of food security and climate change mitigation (FAO 2011; Kiil et al. 2017). Nowadays, between 1.3 and 2 billion tons of food that is produced worldwide is lost or wasted, corresponding to an annual global cost of about USD 1 trillion, of which roughly US\$ 310 billion is in developing countries and US\$ 680 billion in industrialized countries (Fox and Fimeche 2013; Gustavsson et al. 2011). As total food loss in the industrialized world nearly equals the total available food production in Sub-Saharan Africa, there is an urgent call to tackle this issue, and hence to measure what is lost in developed countries (FAO 2011). Notwithstanding the global nature of food loss, Northern America and Europe appear to be performing the worst, with an estimated per capita food loss of 95-115 kg/year, more than ten times higher than in Sub-Saharan Africa and South(-East) Asia (Gustavsson et al. 2011). In the EU alone, nearly $40 \%$ of losses occur during food processing (Buchner et al. 2012), partially due to inefficiencies in the processing system and production management.

There are numerous studies on food waste and loss from the demand-side perspective, i.e. focusing on consumer behavior towards food choice and waste generation at household level (Evans 2011; Stancu et al. 2016; Papargyropoulou et al. 2014; Sheahan and Barrett 2017; Harder et al. 2014; Kantor et al. 1997). However, studies have shown that a typical food product is handled an average of 33 times before it is ever touched by a consumer in a supermarket (Kantor et al. 1997). While this has led to a large body of research on the supply-side, which has targeted food waste and losses at certain levels of the supply chain (e.g. wholesalers, distributors and retailers), analysis at the process level has been largely ignored (Sheahan and Barrett 2017). There are only a few studies emphasizing various elements of sustainable operations, such as product changes, inventory management, handling and packaging, all of which are responsible for food loss (Van Wezel et al. 2006; Flapper et al. 2002; Tadei et al. 1995). Furthermore, there is no empirical study which identifies hotspots of food loss (i.e. stages where substantial/excessive food loss is likely to occur) across the production stages. This study aims to fill these research gaps using the case of Belgium's food processing industries.

While food loss takes place at various stages of the food supply chain, such as harvesting, postharvest, processing and distribution (Martindale 2010; Parfitt et al. 2010), we will examine food loss within an industrial food processing environment through mapping losses at each processing stage (Taleghani 2010; Kennedy et al. 2013). One of the most significant challenges is the collection of reliable data on food loss during the processing stage, especially within an industrial environment. It is therefore crucial to gain insight into this stage and determine the extent of this problem and its causes (hotspots). In order to understand the magnitude of food loss at different stages of food processing, the present study 
estimates loss levels for each step of the production process. As such, this study only concentrates on food losses during the industrial processing phase. At the manufacturing level, there are many reasons for food losses, such as overproduction, deformed products, product and packaging damage, poor housekeeping procedures and poor conformity (Halloran et al. 2014; Beretta et al. 2013). Similarly, spillages, damage and contamination of products may be caused by, for example, operators' negligence, poor handling procedures, and equipment failure resulting in improper seals on packaging. Moreover, food loss may also occur because of poor conformity with respect to any ingredient or product failing to adequately comply with specifications for quality, appearance, flavor, or aroma (Dora et al. 2012). Against this backdrop, this study quantifies food loss and investigates its most important causes through data collection in food processing companies in Belgium.

\subsection{Previous studies}

To access the current knowledge on this topic, a literature review was carried out with a focus on scientific literature over a 12-year period (from 2004 to 2016). Table 1 provides a summary of studies considered for this research. While various studies have to be considered as case studies, applied to different settings, products and stages, together they underline the variability in the assessment of food loss, causes and potential solutions. The analysis highlights the objectives, methods, focus (study location) and findings (hotspots, reasons, solutions) of those studies.

Based on the research considered in these 28 relevant journal articles, there is an interesting trend and focus that can be observed in this field of research. Classification of the 28 articles based on FOCUS (consumer only, processing only, full supply chain), METHOD (secondary data, case study, literature review), and HOTSPOT (if the study identified hotspots of food loss) provides the following breakdown (see Table 2): The majority of the studies focused on the supply chain, with only six focusing on food processing. Twenty-one studies were based on secondary data, while only $50 \%$ of the studies identified hotspots of food loss. Hence, we chose to particularly focus on food processing enterprises and on the identification of food loss hotspots (i.e. stages) using the case of Belgian processing industries.

We further, investigated the specifics of the analysis in these studies to get a better understanding of the current challenges. A study by Beretta et al. (2013), for instance, has quantified food losses in Switzerland at various stages of the food supply chain (agricultural production, postharvest handling and trade, processing, food service industry, retail, and households). This study identified hotspots and analyzed the reasons for losses based on data from 31 companies within the food chain including public institutions and food associations. The energy balance shows that $48 \%$ of the total calories produced are lost across the supply chain. Similarly, Nahman et al. (2012) quantified the household food waste stream in South Africa. They estimated the economic (monetary) value of the wasted food as well as the costs associated with disposing putrescible food waste to landfills. Costs associated with the disposal of food waste to landfills are quantified based on estimates of the financial and external costs associated with landfilling. For household food waste alone, the costs to society are estimated at approximately US $\$ 2.7$ billion annually in South Africa.

Some studies also focused on the environmental consequences of the food loss, such as Fehr et al. (2002), who determined the occurrence of fruit and vegetable waste at the wholesale and retail levels in Brazil. Similarly, Darlington et al. (2009) investigated various categories of waste and generated three analytical methods for the support of waste minimization activities by food manufacturers. They found that waste due to overproduction accounts for $20-40 \%$ 


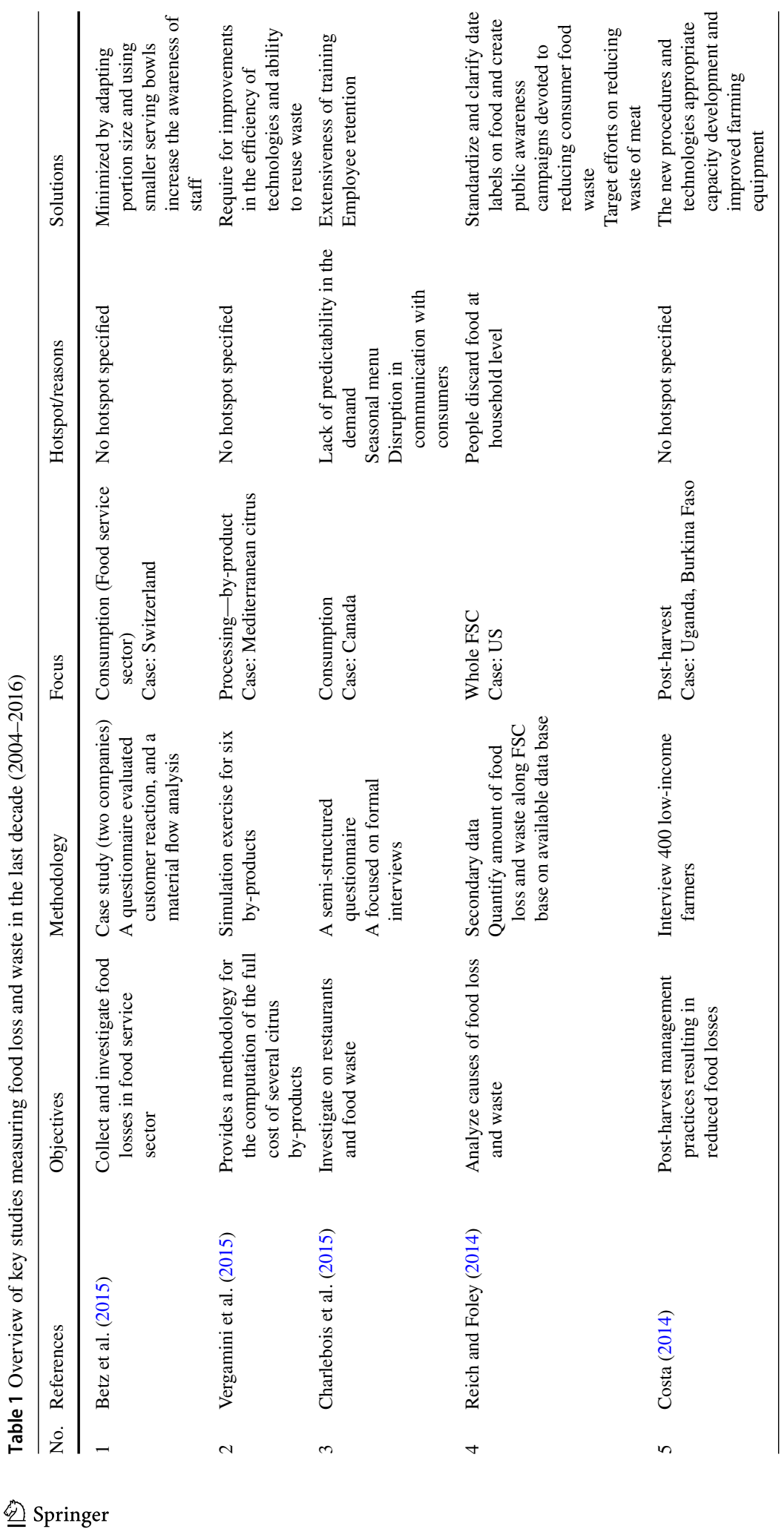




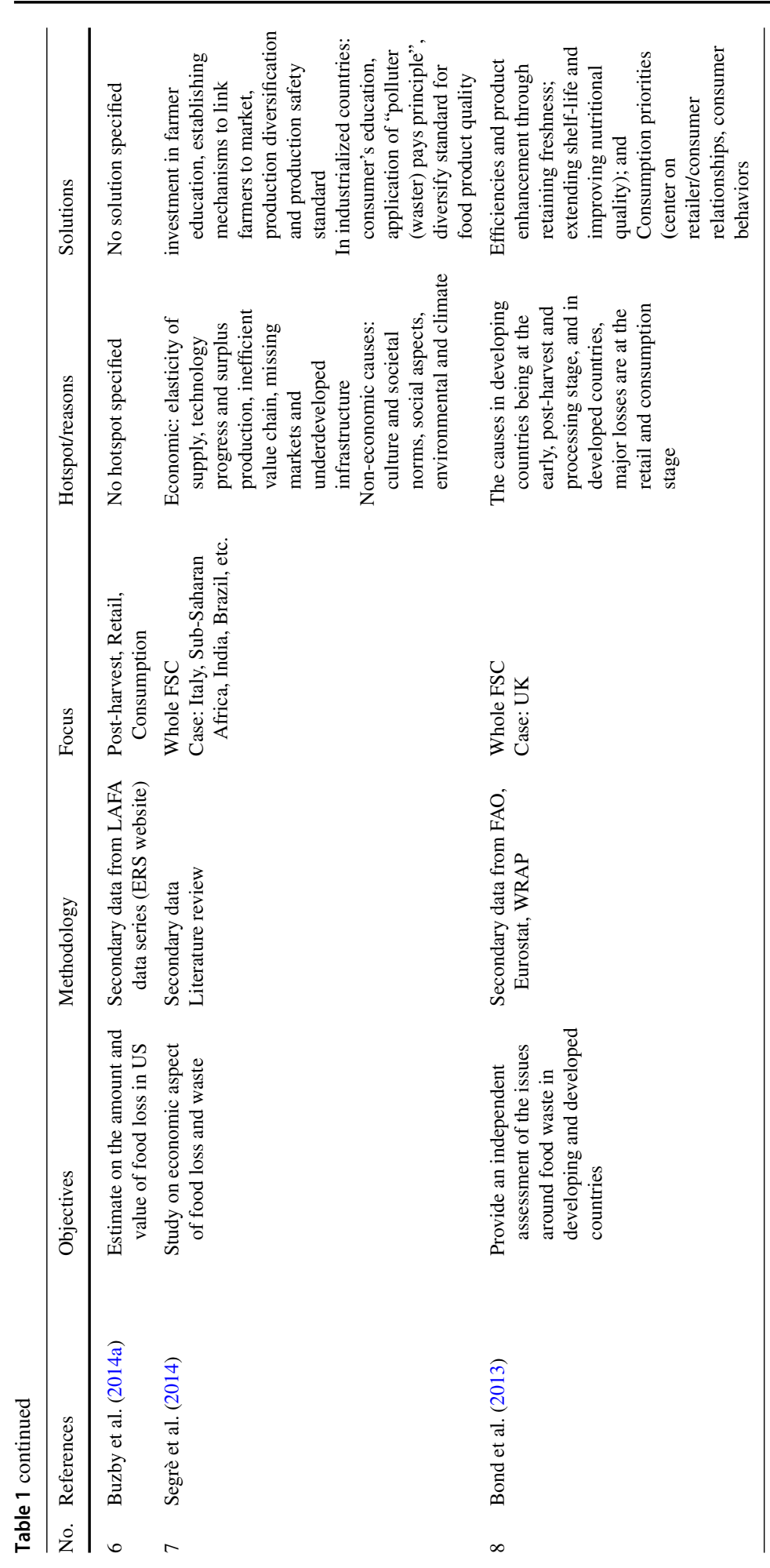




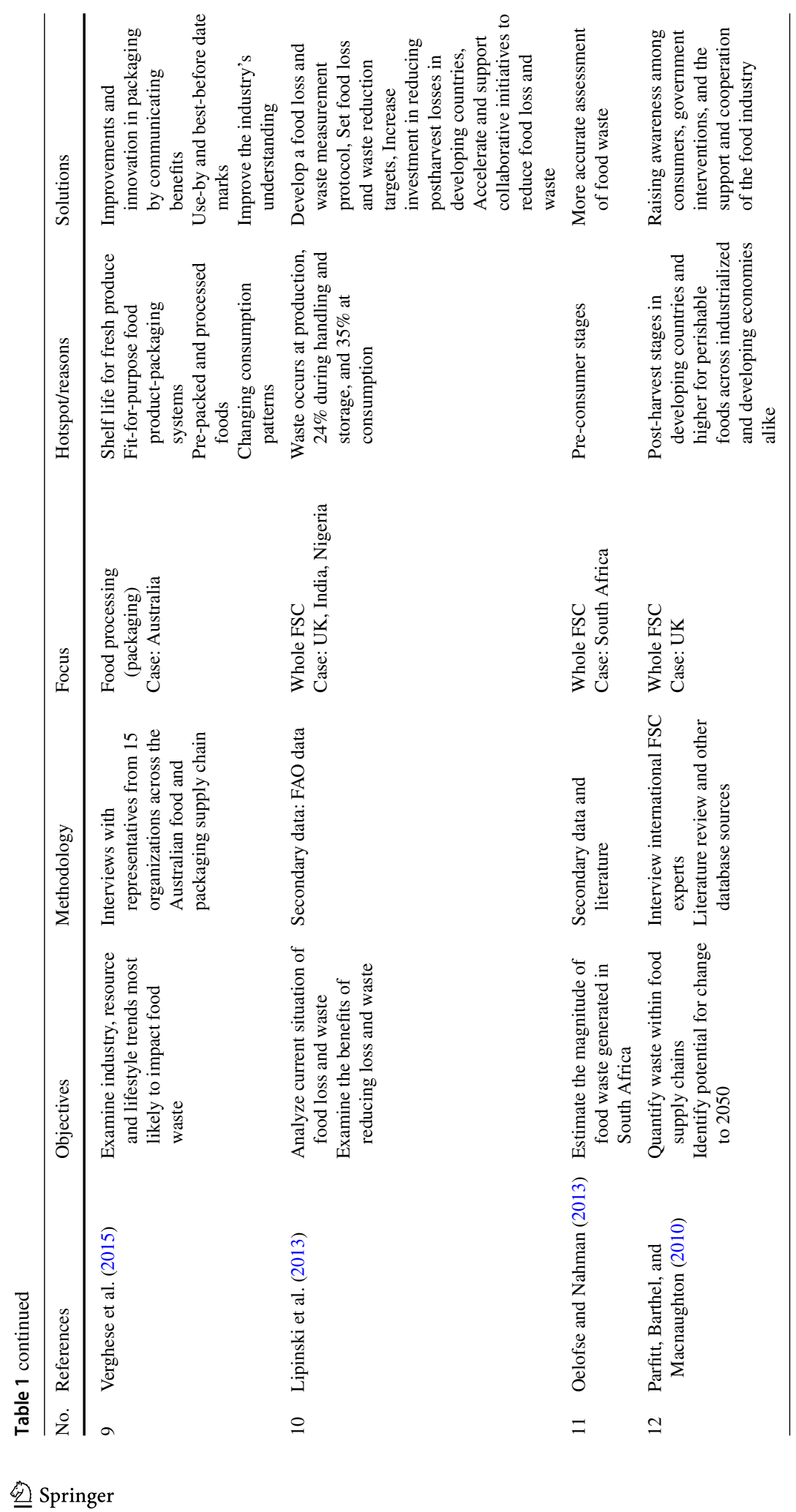




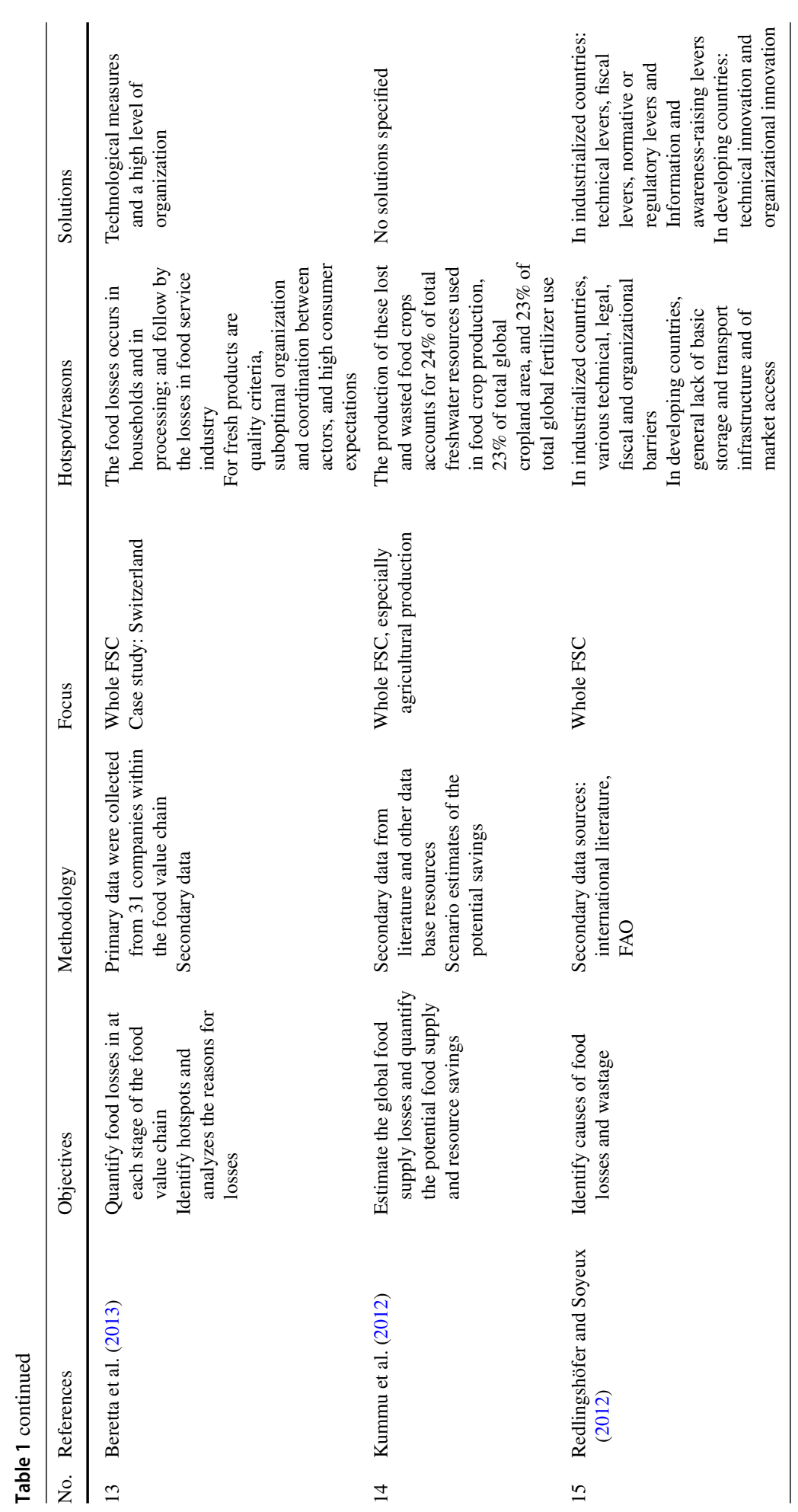




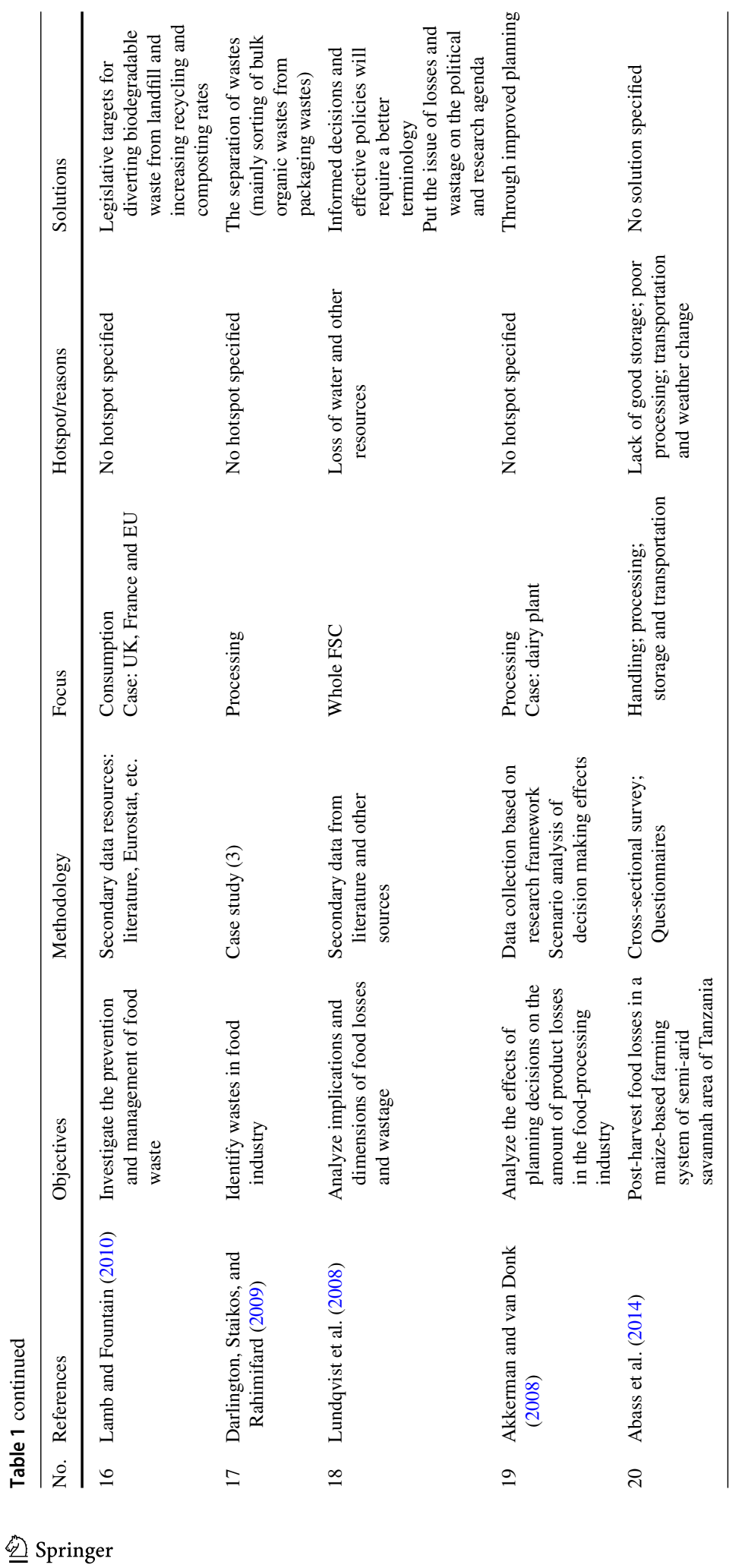




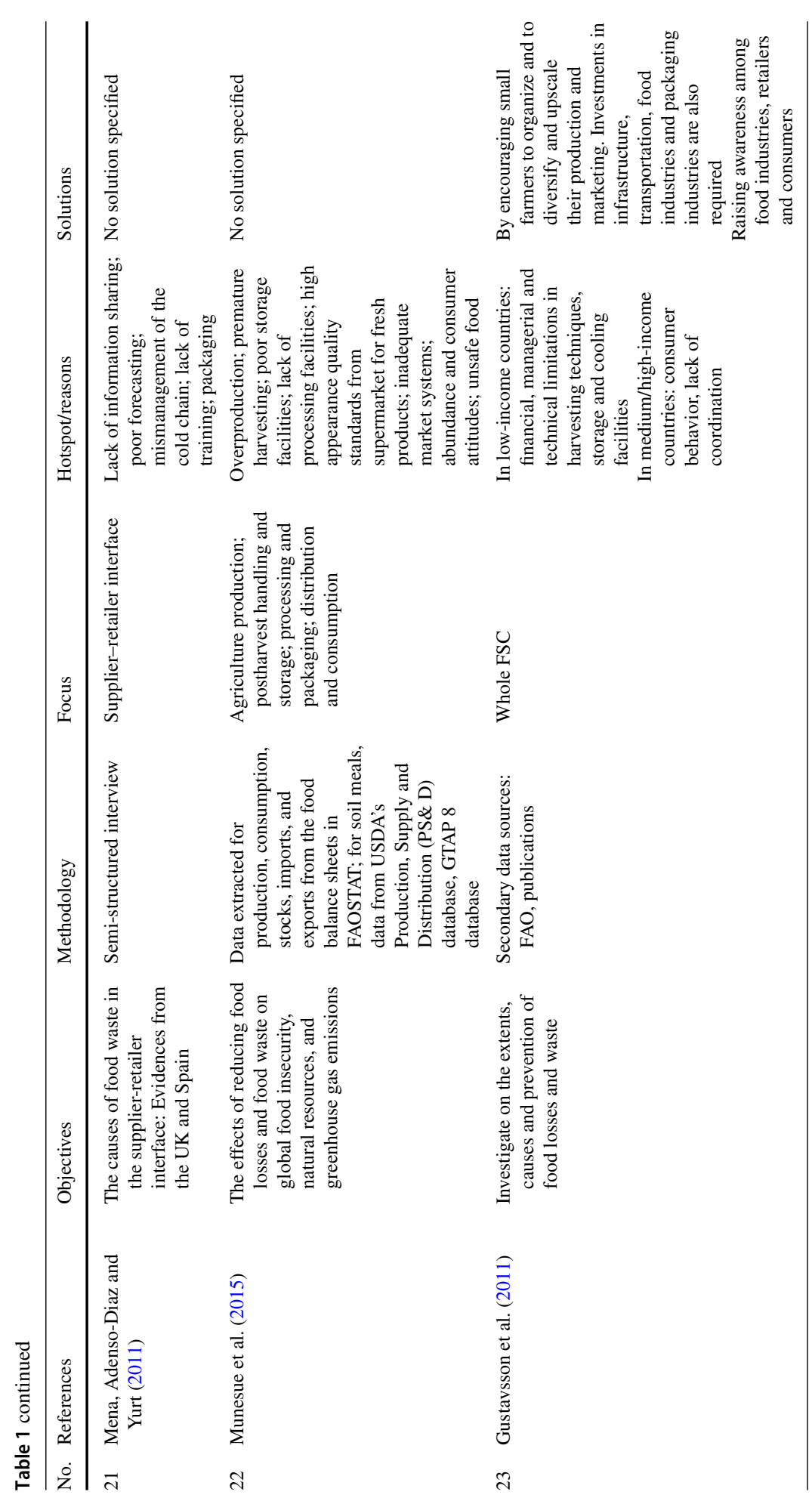




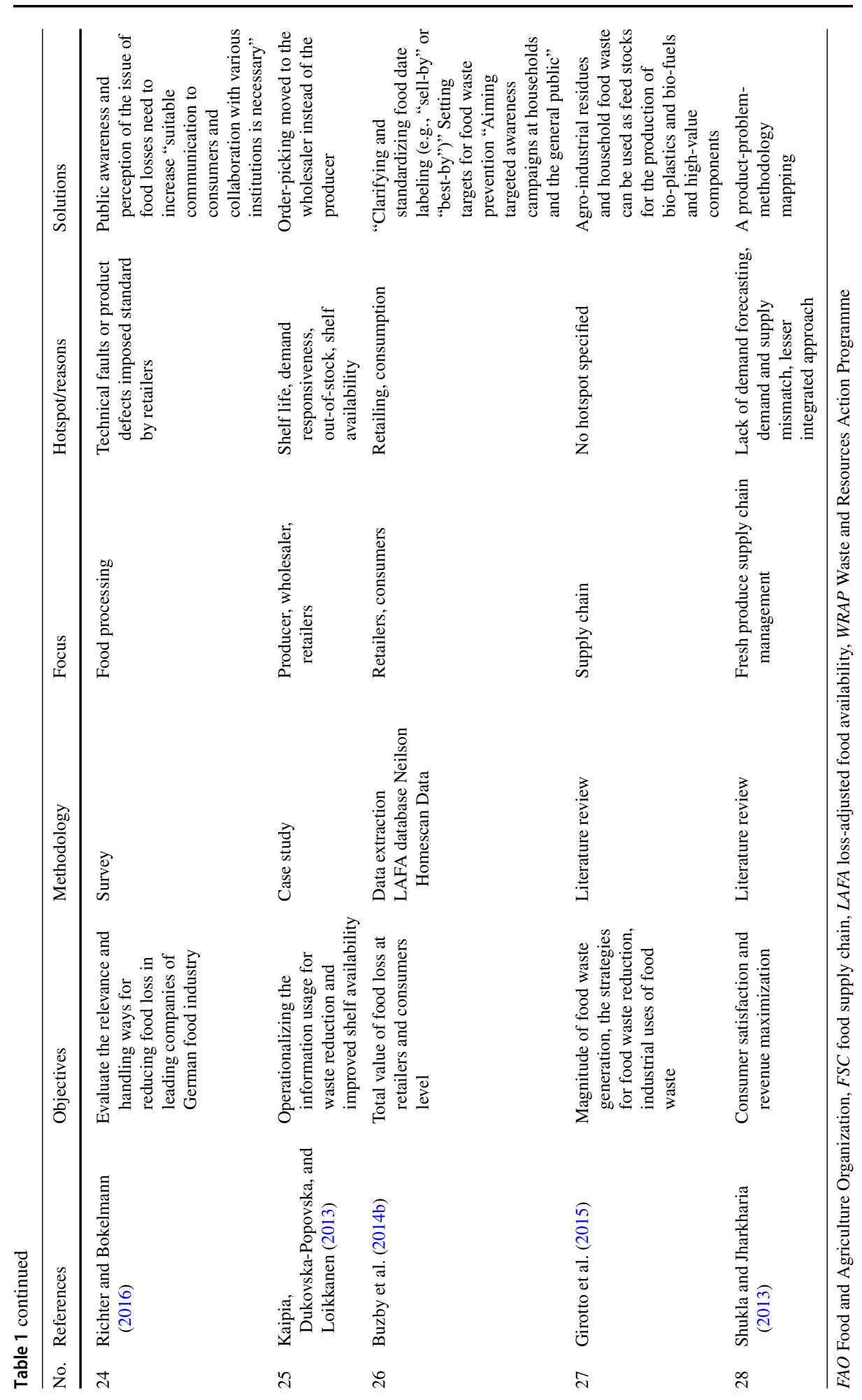


Table 2 Summary of key studies measuring food loss and waste in the last decade (2004-2016), targeted chain actor (focus), applied method and inclusion of hotspot identification

\begin{tabular}{lrlrll}
\hline Focus & & Method & \multicolumn{2}{c}{ Hotspot } \\
\hline Consumer & 3 & Secondary data & 21 & Yes & 14 \\
Processing & 6 & Case study & 5 & No & 14 \\
Supply Chain & 19 & Literature review & 2 & & \\
\hline
\end{tabular}

of the material waste generated by manufacturers of convenience food (such as ready-meals) and is attributed to the demands placed on the manufacturer to provide orders to supermarkets within a short timeframe. By using a practical example, their study provided measures by which food industry waste can be identified. Lebersorger and Schneider (2011) discussed a model for determining the proportion of food waste in household waste composition studies. They suggest that in order to avoid a significant loss of information, waste should not be sieved before sorting and packed food waste should be classified into the relevant food waste category. Engström and Carlsson-Kanyama (2004) examined food losses in four food service institutions in Sweden. Their results showed that about one-fifth of the food was lost. Thereby, plate waste is considered the single largest source of loss, with about $11-13 \%$ of the amount of food served being lost. They further demonstrated the considerable economic and environmental impacts of current levels of food loss in Swedish food service institutions. Buzby and Hyman (2012) compiled estimates of the amount and value of food loss for more than 200 individual food companies in the United States. By aggregating data from the US Department of Agriculture's Economic Research Service, the total value of food loss at the retail and consumer levels in the United States was estimated at $\$ 165.6$ billion. This is almost $10 \%$ of the average amount spent on food per consumer in 2008 and over $1 \%$ of the average disposable income. Three food groups mainly accounted for food loss at these levels: meat, poultry, and fish (41\%), vegetables (17\%) and dairy products (14\%). Eriksson et al. (2012) analyzed the flows of fruit and vegetables at six Swedish retail stores, both by analyzing recorded data and by performing physical measurements. They found that the total wasted fresh fruits and vegetables were $4.3 \%$ of the delivered quantity. The largest category was pre-store waste (goods rejected at delivery, $3.01 \%$ ), followed by recorded $(0.99 \%)$ and unrecorded in-store waste $(0.3 \%)$. A positive correlation between unrecorded in-store waste and total waste was found, indicating that a thorough recording of waste could be an effective way to reduce retail waste of fresh fruits and vegetables. The study also found that the practice of exhibiting large amounts of delivered goods was recognized as the main reason for the waste (Goubergen et al. 2011).

Further, a study in the EU emphasized the negative impact of inappropriate processing systems and ineffective production operation management (BCFN 2012). In the "Preparatory study on food loss across EU 27" report, the European Commission (2010) also pointed out that logistical and technical issues are major causes of food loss in the wholesale/retail and manufacturing sectors. At processing level, technical malfunctions play an important role in generating food loss (such as overproduction, product damage or misshapen products), which often requires rework or has to be discarded entirely. In addition, problems arising during packaging also result in food spoilage, though to a lesser extent. Within the food and drink industry, for example, a large proportion of food is wasted as a result of legislative restrictions on odd shaped produce, especially with respect to the size and shape of fruit and vegetables (EC 2010).

Furthermore, it is important to highlight differences in causes within a product category that are attributable to company size. The shape/size of ingredients and products is consid- 
Table 3 Summary of key reports measuring food loss and waste, targeted chain actor (focus), applied method and inclusion of hotspot identification

\begin{tabular}{lc}
\hline Reports & Objective, actors involved and limitation \\
\hline Food and Nations (2013) & $\begin{array}{c}\text { This report identified "Global environmental hotspots" by collecting } \\
\text { high level (macro) data from various supply chain members. } \\
\text { There is no information or data showing the micro level (e.g. } \\
\text { activities at the processing stage) }\end{array}$ \\
Turopean Court of Auditors (2016) & $\begin{array}{l}\text { This study audits of policies on food waste and how its impact } \\
\text { supply chain members }\end{array}$ \\
Thistavsson et al. (2011) & $\begin{array}{l}\text { This report assessed the magnitude, identifies causes of food losses } \\
\text { and possible ways of preventing them in the chain. However, the } \\
\text { micro level information is ignored }\end{array}$ \\
This report provides strategies for reducing food loss and waste for \\
chain members. Nevertheless, there is limited focus on micro level \\
strategies for the processors \\
This study analyses of reasons of food loss and prevention strategy \\
in the chain. But there is no references to the inside circumstances \\
of members \\
This report estimates the high level food waste arising in the EU-28 \\
and ignored the micro picture
\end{tabular}

ered as the most important cause of food loss in the food industry (Dora et al. 2012). In fact, the physical properties of the components of food and drinks can have important impacts on taste, texture, appearance, stability, process-ability and functionality of the final product. Food products and their ingredients may have a specific shape or form (powders, emulsions, suspensions or pellets) that requires certain production processes and techniques. This specification often creates a large proportion of by-products and material waste (Van Goubergen et al. 2011). Many kinds of foods, such as grains, fruits, and vegetables, have special shape features that represent their overall quality. Therefore, semi-finished or finished products that do not meet the requirements related to shape or size have to be reworked or are thrown away (food loss).

Considering the nature of the subject area where many global organizations are active, and country-specific analysis has been conducted, we have also identified relevant reports to provide additional insights on current trends (Table 3).

These relevant reports prepared by major international organizations such as the FAO, the UN, the WRI, and the EU, reveal an interesting pattern: (a) there is a limited number of studies that examine each processing stage of the production level in a manufacturing environment; (b) there is no study which identifies hotspots of food loss across specific production stages; and (c) there are few studies examining the importance of various elements of sustainable operation, such as product changes, inventory management, handling, packaging, that are responsible for food loss.

\subsection{Aim of the study}

Given these knowledge gaps, this study aims to answer the following research questions:

(1) Which are the hotspots of food loss at different stages of food production?

(2) What are the major causes of food loss across different production stages and product categories? 
Childe (2011) highlighted, it is crucial that researchers work closely with industries in order to better understand the challenges faced by industries. This study targets 47 food processing companies to compile and analyze the magnitude and hotspots of food losses in the context of Belgium (a developed economy). In recent years, the Belgian government has initiated various projects and initiatives to reduce food loss, especially at the processing and consumption stages (Wille 2015; Food Drink Europe 2014). Nevertheless, with an annual total food loss estimated at 3.6 million tons, Belgium is still ranked among the most problematic EU member states (Roels and Van Gijseghem 2011), which makes it a valuable case for food loss measurement.

\section{Methodology}

\subsection{Data collection method}

To quantify food loss in food processing companies and to identify reasons for such loss, researchers used primary data which were mainly collected and gathered through a survey in multiple companies (Aschemann-Witzel et al. 2017), supplemented with documentary analysis and observations. Cases - here, food processing companies-are objects of study and are considered to be complex functioning units, contemporary, and investigated in the natural context (Gillham 2000; Yin 2013). Therefore, a combination of qualitative and quantitative research, such as survey, observation and documentary analysis, is often required. Given that food loss is a complex, multifaceted concept that may occur throughout all operations in food processing, associated with a multifaceted array of causes, we have collected data based on a survey that was completed through a company visit. Like case study research, this involves an in-depth study of particular situations/processes and a detailed analysis within and between sectors. By targeting food loss in Belgian food processing companies, this research will not focus on a single case but will examine a number of cases, analyzing the current situation on the work floor, to formulate more general conclusions (Gummesson 2000) within and across subsectors of food processing. Thereby, we apply the approach of Dora et al. (2016) to the Belgian food industry context.

A three-step process was used for the data collection in this research. First, the researchers launched an open call for participation to all food processing companies in Belgium. All members of the Belgian Food Industry Association were informed about this study through e-mail. From all the companies who were interested, a selection of companies was made in close consultation with the association to ensure that the sample included both small and large companies and covered a broad spectrum of the subsectors in the Belgian Food Industry. In total, 47 companies participated in this study. These companies operated in different subsectors and were located in different regions across Belgium, thus ensuring a diverse coverage of the targeted sector. The companies were active in the following sectors: vegetables and fruit processing; drinks and chocolates manufacturing; grain mill products; baking and dairy processing; sauces; slaughter houses; and ready meal processing. Due to the diversity in scale and types of production, location, etc.; the firms were assumed to represent their respective segments in the Belgian market. Table 4 provides an overview of the key descriptive of the food processing companies that participated in the study.

Secondly, each company was visited by the same two researchers, who adopted a similar data collection approach in each selected company. Thereby, operators, operating managers, and general managers were considered as respondents of this study, given their sufficient 
Table 4 Description of food processing companies $(n=47)$

\begin{tabular}{|c|c|c|c|c|c|c|c|c|c|}
\hline \multirow[t]{2}{*}{ Subsector } & \multirow[t]{2}{*}{$\mathrm{n}$} & \multirow[t]{2}{*}{ Average FTE } & \multirow[t]{2}{*}{ Shelf life } & \multicolumn{2}{|c|}{$\begin{array}{l}\text { Turnover } \\
\text { (million } € \text { ) }\end{array}$} & \multicolumn{2}{|c|}{$\begin{array}{l}\text { Production } \\
(1000 \mathrm{~kg} /(\mathrm{L})\end{array}$} & \multicolumn{2}{|c|}{$\begin{array}{l}\text { No. of } \\
\text { employees }\end{array}$} \\
\hline & & & & Min & Max & Min & Max & Min & Max \\
\hline $\begin{array}{l}\text { Vegetable and } \\
\text { fruit }\end{array}$ & 7 & 146 & 185 & 2.1 & 223.6 & 2000 & 340.000 & 15 & 414 \\
\hline Ready meal & 5 & 227 & 134 & 7.5 & 14.3 & 694 & 19.000 & 43 & 131 \\
\hline Bakery & 9 & 173 & 375 & 8.0 & 26.8 & 240 & 45.000 & 6 & 550 \\
\hline $\begin{array}{r}\text { Grain mill } \\
\text { products }\end{array}$ & 4 & 182 & 452 & 16.1 & 25.0 & 21.000 & 75.000 & 37 & 644 \\
\hline Sauces & 3 & 240 & 480 & 19.7 & 155.6 & 10.000 & 29.030 & 70 & 278 \\
\hline Drinks & 7 & 110 & 113 & 2.7 & 196.7 & 12.865 & 350.000 & 20 & 480 \\
\hline Chocolates & 6 & 192 & 212 & 0.5 & 1.7 & 25 & 294.745 & 3 & 985 \\
\hline Dairy & 4 & 209 & 240 & 2.7 & 62.6 & 980 & 25.240 & 9 & 165 \\
\hline $\begin{array}{l}\text { Meat + Slaugh- } \\
\text { terhouse }\end{array}$ & 2 & 94 & 34 & 9.8 & 125.2 & 4.760 & 104.000 & 23 & 150 \\
\hline
\end{tabular}

FTE full time equivalent

experience and understanding of the production process and the production strategy of their companies. The date and time for the meetings were arranged via e-mail or phone. During the visit, the entire production process was screened and interviews with operators (17), operation managers (19) and general managers of the companies (11) were carried out to complete the survey. One researcher guided the interview, while the other took notes and completed the questionnaire. In many instances, multiple respondents were involved in the provision of data. In cases where data could not be delivered during the visits, data estimates were provided at a later stage through e-mail or phone. In this way, data was derived from interviews and on-site observations, but also from relevant documents in order to gain an overall insight into the process and food loss (Eisenhardt 1989). Thereby, appropriate measures were taken to reduce observer bias such as training interviewers to ask questions in the same way and distributing the tasks (interviewing versus making notes) between two researchers (Yin 2013).

Thirdly, after the visits, the information from the interviews was complemented with the researchers' observations/notes. Thereby, respondents could also provide feedback on the collected data to ensure that it was reliable for further analysis. This combination of data types, i.e. survey, observations and documentary analysis, can be highly synergistic and is therefore referred to as a triangulation method (Jick 1979). It is important to note, however, that this study focuses on the survey results, as the observation and documentary results were only used as input for the survey or to support the findings.

\subsection{Questionnaire design}

This study aims to gather information on perceptions and experience of food loss in a number of Belgian food processing companies. Thereby, food loss was defined as either (parts of) raw materials or products that are edible but somehow lost for human consumption (e.g. cutting waste, wrong shape), or loss of water if this was added as an ingredient (e.g. drinks produced, cooked pasta) (Dora et al. 2013a, b). This excludes (parts of) commodities or products which are not edible for humans: (1) secondary streams (waste and by-products) 
e.g. peelings, bones, beet pulp; (2) products that are reworked e.g. dough residues; (3) finished products that are given away e.g. to food banks; (4) financial losses or giveaways e.g. bottle overfilling, lower quality at lower price; or (5) weight loss caused by water that is extracted during processing e.g. baking or dried products. We focus on quantitative food losses-i.e. the decrease in mass of food-rather than on loss of quality (Segrè et al. 2014).

A semi-structured questionnaire was designed and adopted to collect primary data through our multiple case study approach. In order to achieve the desired information, the questionnaire was tested in a food company and adjusted based on feedback from the Belgian Food Industry Association, in order ensure that it was targeted, clear and relevant. The questionnaire includes five main sections. The first section comprises companies' general administrative information, such as operating sector, types of products, production capacity, number of employees and annual turnover. The second part focuses on the identification of food loss and contains questions related to the composition, conveyance and proportion of food loss at three stages of food processing (i.e., 1. Before production: planning/ordering, storing, inventory management; 2 . Production: processing and packaging; 3 . After-production: inventory management, transport and buyer contracts). Respondents were provided with a definition of food loss so that they had a good understanding and were able to quantify the magnitude of the food loss within the company. For each stage, food loss data was based on estimates provided by the respondents. These estimates were often supported by or complemented with observations or documentary analysis. All food loss data were expressed in (or converted into) $\mathrm{kg}$. In the next section, major reasons/causes for food loss were listed, building upon Dora et al. (2016), and their perceived contribution during processing was assessed. Following the three stages of processing, respondents indicated the magnitude/level of food loss per cause (i.e. $0=$ no loss, $1=$ little loss, $2=$ loss, $3=$ substantial loss and $4=$ excessive loss).

As our study focused on formal interviews onsite, the combination of quantitative data collection and observations from the researchers is expected to increase the accuracy and reliability of the data and information collected. Furthermore, in addition to the closedended scale questions, the questionnaire also involved several open-ended questions in order to further explore the respondents' answers and provide flexibility for interview discussions (e.g. specific type and destination of food that is lost). However, given the individual, nonstandardized nature of this data, this information was not used for the main data analysis.

\subsection{Data analysis}

All quantitative data from the questionnaire (derived from the interviews and the documentary analysis) were inserted into an Excel database, to which the researchers' own observations were added for clarification and to facilitate the interpretation of results. This database allowed quantification of the magnitude of food losses for each selected company. We have analyzed the results in two ways, by comparing the results between subsectors (i.e. absolute and relative food loss figures, financial costs, importance of food losses per cause and per stage) as well as between stages, regardless of the subsector (i.e. importance of food losses per cause and impact of each stage on total food loss). To further analyze the quantitative data on the (causes of) food losses, SPSS statistical software was used. The magnitude of food loss was categorized at three levels (i.e. loss, substantial loss and excessive loss) which were analyzed and represented based on three stages of food processing: before, during (with processing and packaging as a sub-stage), and after processing. By doing so, important causes of food loss, as defined from previous literature, can be identified and illustrated across different food sectors. Descriptive statistics were used to explain company/product characteristics and the 
Table 5 Key figures of food loss in the food processing companies $(n=47)$

\begin{tabular}{|c|c|c|c|c|c|c|c|c|c|c|}
\hline \multirow[t]{2}{*}{ Subsector } & \multirow[t]{2}{*}{$\mathrm{n}$} & \multirow{2}{*}{$\begin{array}{l}\text { Production } \\
\text { Average }\end{array}$} & \multicolumn{3}{|c|}{ Quantity of loss kg } & \multicolumn{3}{|c|}{ Food loss $\%$} & \multicolumn{2}{|c|}{ Financial cost $£$} \\
\hline & & & Min & Max & Average & Min & $\operatorname{Max}$ & Average & $\operatorname{Max} £^{\mathrm{a}}$ & $\begin{array}{l}\text { Max } \\
£ / \text { unit }^{\mathrm{a}}\end{array}$ \\
\hline $\begin{array}{l}\text { Vegetables } \\
\text { and } \\
\text { fruit }^{b}\end{array}$ & 7 & 111,929 & 1.40 & $17,907.40$ & 5184 & 0.01 & 14.92 & 4.63 & \multicolumn{2}{|c|}{$21,752,1661.22$} \\
\hline $\begin{array}{r}\text { Ready } \\
\text { meal }\end{array}$ & 5 & 6300 & 38.08 & 551.77 & 233.13 & 2.86 & 6.13 & 3.70 & \multicolumn{2}{|c|}{$655,2492.72$} \\
\hline Bakery & 9 & 9629 & 4.41 & 1430.84 & 378.74 & 0.22 & 7.36 & 3.93 & \multicolumn{2}{|c|}{$2,069,2171.69$} \\
\hline $\begin{array}{l}\text { Grain } \\
\text { mill } \\
\text { prod- } \\
\text { ucts }\end{array}$ & 4 & 42,750 & 30.00 & 2023.00 & 976.25 & 0.07 & 5.82 & 2.28 & \multicolumn{2}{|c|}{$525,8250.83$} \\
\hline Sauces & 3 & 16,343 & 2.56 & 610.00 & 212.52 & 0.01 & 6.10 & 1.30 & \multicolumn{2}{|c|}{$1,200,0961.97$} \\
\hline Drinks & 7 & 129,847 & 60.00 & 6220.00 & 1760.46 & 0.23 & 7.71 & 1.36 & \multicolumn{2}{|c|}{$3,496,2990.56$} \\
\hline Chocolate & 6 & 56,495 & 0.27 & 1075.00 & 250.43 & 0.35 & 5.00 & 0.44 & \multicolumn{2}{|c|}{$6,310,7045.87$} \\
\hline Dairy & 4 & 11,880 & 8.76 & 56.00 & 21.38 & 0.04 & 1.02 & 0.18 & \multicolumn{2}{|c|}{$36,5654.18$} \\
\hline $\begin{array}{l}\text { Meat + } \\
\text { slaugh- } \\
\text { ter- } \\
\text { house }\end{array}$ & 2 & 54,380 & 0.50 & 156.00 & 78.25 & 0.01 & 0.15 & 0.14 & \multicolumn{2}{|c|}{10332.07} \\
\hline All & 47 & 48,839 & & & 1011 & & & 2.07 & & \\
\hline
\end{tabular}

${ }^{a}$ Maximum refers to the company within a subsector which is characterized by the largest financial losses. Financial data is expressed in pounds $(£ 1=€ 1.118)$

${ }^{\mathrm{b}}$ Vegetables and fruit: combination of frozen or fresh

occurrence and causes of food losses. Further analysis involved regression models applied to determine the impact of each stage on food loss. Thereby, the percentage food loss constituted the dependent variable whereas independent variables were based on index scores that were created by aggregating responses (magnitude levels) for the importance of food loss causes at each stage of processing. Graphical techniques were also used to represent the results.

\section{Results}

\subsection{Characteristics of food companies}

Of the 47 food companies studied, the majority produce bakery, drinks, and vegetable and fruit products (Table 5). While other kinds of companies were fairly represented, those processing meat products were relatively few. The average production ranged from 6300 tons (ready meals) to 129,847 tons (drinks), highlighting a wide variation among companies. There were fewer employees in food companies that had the largest production relative to those with lower production levels, which reflects the utilization of mechanized production as compared to man power needed.

Table 5 further reveals that in terms of quantity, the vegetable and fruit sector contribute the highest percentage of loss, followed by ready meal companies. However, in terms of financial cost of food loss, the chocolate and ready-meal subsectors top the list. 
Table 6 Hotspots of food losses. Impact of each stage on the relative proportion of food loss, by multivariate regression analysis

\begin{tabular}{lcc}
\hline & $\beta$ & $\mathrm{p}$ \\
\hline Before production & -0.75 & 0.07 \\
During production & 0.18 & 0.05 \\
After production & 0.40 & 0.31 \\
& $\mathrm{R}^{2}: 15.8 \%$ & \\
\hline
\end{tabular}

Effect sizes $(\beta)$ of the regression analysis refer to the impact of each step in the food process (based on the aggregated importance of all food loss causes within a stage; see also Fig. 2, first panel) on the amount of food losses (expressed as percentage of food production; see Table 5)

\subsection{Magnitude and hotspots of food loss}

On average, the amount of food that is lost in targeted companies accounts for $2.1 \%$ of the total production, regardless of the subsector (Table 5). Based on the average production of 48.839 tons across subsectors, this corresponds with an average loss of 1011 ton. The highest and lowest proportions of food losses were observed among vegetables and fruits $(4.63 \%)$ and meat $(0.14 \%)$ companies, respectively. However, there are wide variations from one company to another, even within a subsector.

To further examine the impact of the stages of production on the share of food loss in total production, multivariate regression was conducted (Table 6). The results indicate that all stages together account for $16 \%$ of the variation observed in the average percentage of food losses in food processing companies. Thereby, the production stage is considered the most important hotspot for food loss. At this stage, a significant positive effect was observed. For every increase in the level of magnitude of causes identified, the average proportion of food losses significantly increased by $0.18 \%$. There was, however, no significant association observed between the other stages of processing and the proportion of food losses occurring in processing companies.

\subsection{Causes of food loss}

The results in Fig. 1 depict the amount of food that is perceived to be lost per cause of loss, divided according to processing stage: (a) before-production (planning/ordering, storing, inventory management); (b) production (processing and packaging); and (c) after-production (inventory management, transport and buyer contract).

Before production, three main causes of food loss (incorrect orders, suboptimal storage and inventory management) generated substantial losses in $4.3 \%$ of the companies, while only $2.1 \%$ of companies reported a level characterized as excessive losses.

During the production stage, only incorrect stacking was not perceived as a main cause of food loss. Four out of twelve causes were associated with all three magnitudes/levels of food losses (i.e. loss, substantial loss or excessive loss). Regardless of the level of food loss, poor transportation, interrupted production, product changes, human errors and product defects were reported as causes in at least one in five companies. Furthermore, there were variations with respect to the occurrence of substantial or excessive losses. While more than $10 \%$ of the companies reported substantial losses arising from product changes $(13 \%)$ or human errors 


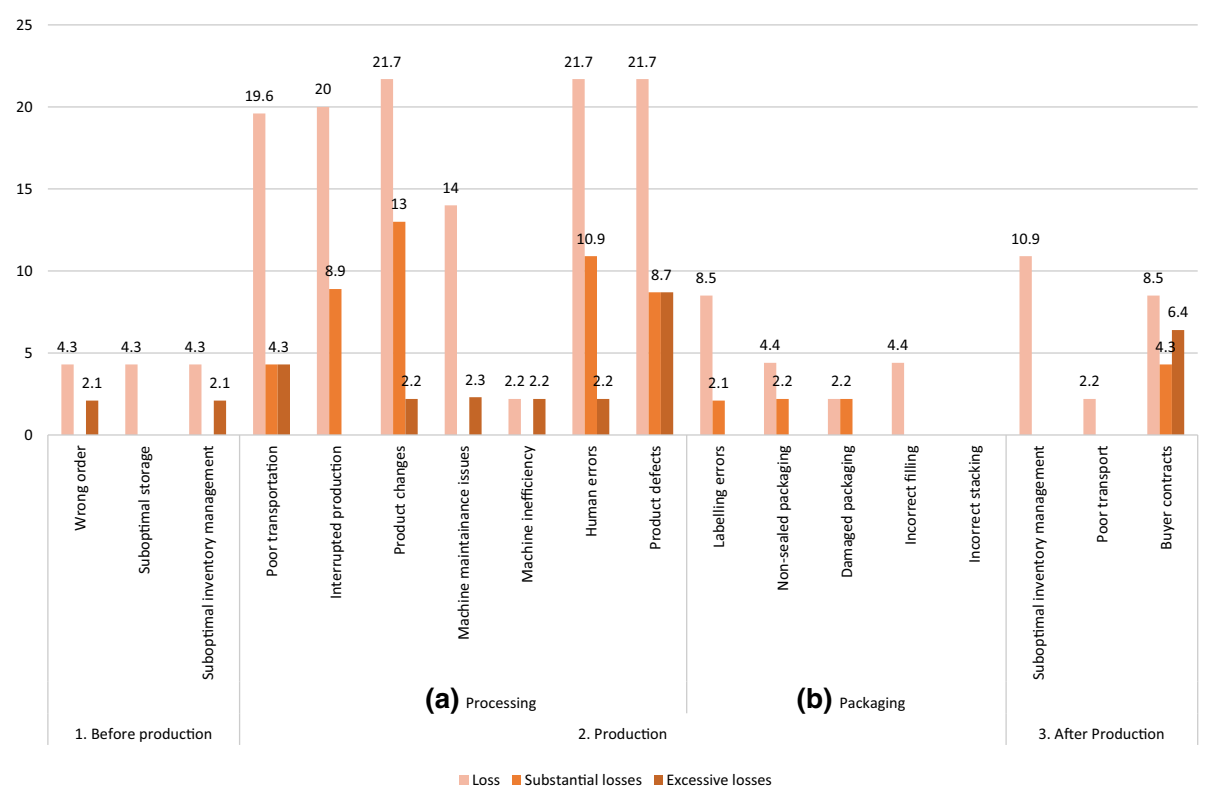

Fig. 1 Perceived food losses, per cause and stage, in \% of sample

$(10.9 \%)$, excessive losses were mostly linked to product defects $(8.7 \%)$ and buyer contracts $(6.4 \%)$.

When looking at the two stages within production, losses are mostly generated at the processing rather than the packaging stage. With respect to processing, a relatively large number of companies $(\sim 20-22 \%)$ indicated losses due to five causes related to processing, while excessive losses were associated with six causes (i.e. poor transportation, product changes, machine maintenance issues, machine inefficiency, human errors and product defects), and occurred in $2.2-8.7 \%$ of companies. For the packaging stage of production, notable sources of non-excessive losses are labelling errors and non-sealed and damaged packaging.

Finally, food loss after production was mainly generated because of sub-optimal inventory management ( $10.9 \%$ of companies) and buyer contracts $(8.5 \%)$, of which only the latter also led to more substantial (4.3\%) and excessive losses $(6.4 \%)$ in a few companies.

Figure 2 visualizes the mean food loss scores of the most important causes of food loss in each of the food subsectors. The findings reveal substantial differences between subsectors with respect to the most important causes. Buyer contracts, mostly occurring at the afterproduction stage, exhibited the highest mean for the ready meal and sauce subsectors. Product defects, which mainly occur during food production, were found to be an important cause of food loss in the vegetable and fruits, ready meal, bakery and chocolate subsectors. Human errors and poor transport caused food loss in all food subsectors, except for the vegetables and fruits sector and sauce producing companies, respectively. The score for product change was in between loss and substantial loss for ready meals, bakery, vegetables and fruits, chocolate and drinks. Machine issues such as poor maintenance and inefficiency were important causes of food loss in the ready meal, vegetables and fruits, chocolate, drinks, grain mill products and sugar sectors. Causes related to food loss during packaging, which mainly occurred in dairy, sauces, grain mill and sugar processing companies, obtained the lowest scores. 

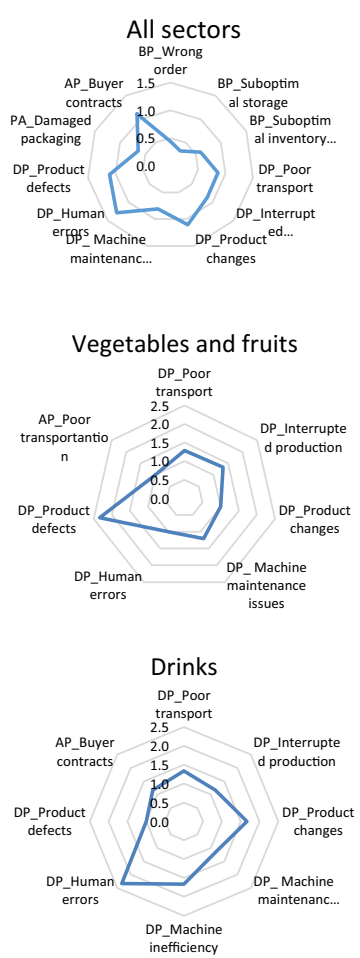
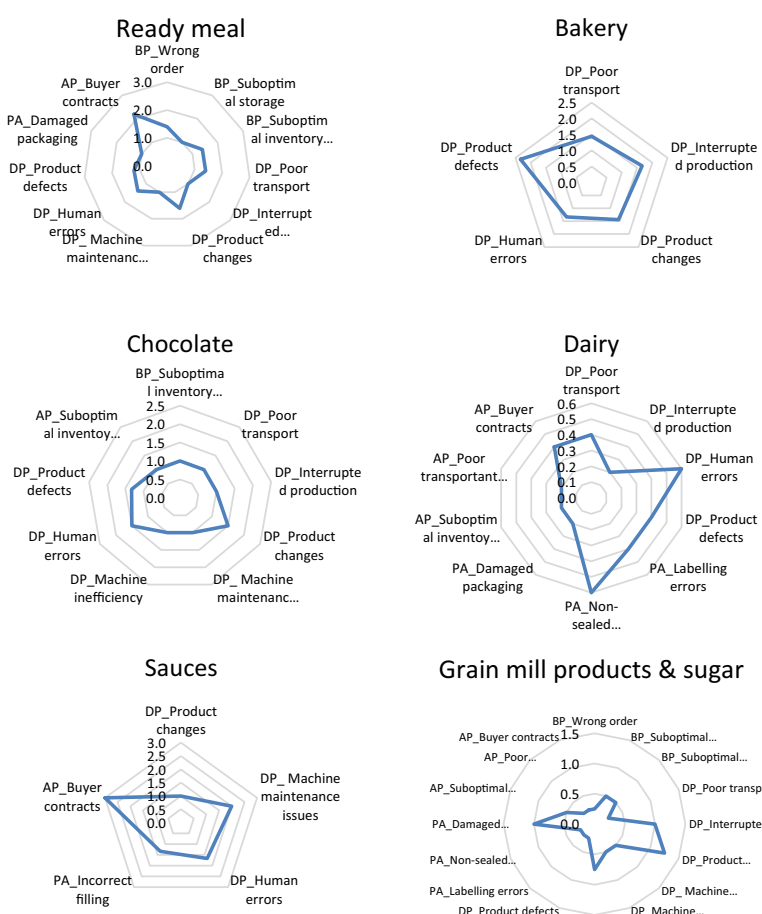

Grain mill products \& sugar
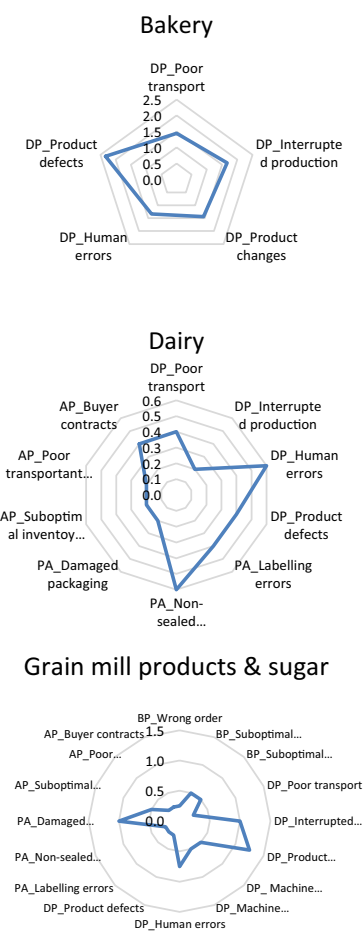

Fig. 2 Importance of food loss causes before, during and after production, in mean, aggregated and per subsector. $B P$ before production, $D P$ during production, $A P$ after production. Note Means are derived from the perceived importance of food loss, which is measured on a 5-point scale (' 0 ' $=$ no loss, to ' 5 ' $=$ excessive loss)

Further, the qualitative information from the operators/operation managers confirm that human errors are the main causes of food loss. Specifically, bad handling of food by employees often originates from lack of knowledge, and low level of training. Moreover, in some case companies, there is generally low involvement of employees with respect to handling. For instance, the companies instruct their employees to follow first in first out (FIFO) principles, but it was observed that these principles are not properly followed, resulting in food loss.

Another cause of food loss among the food manufacturers is the change of products in the production line (product changes), e.g. changing to tomato sauce from mustard chili sauce on the same line. A change of product processed within a line can result in loss of material, especially the residues on the line. Importantly, remaining material from the previous product processing may affect the quality of later products on the line. Considering the quality assurance requirement in food processing, cleaning between the product changes was found to be a major source of food loss.

Interruptions to production, such as malfunctioning processing equipment/techniques, interrupted production lines and cold chains, is an important reason for food loss among the Belgian food manufacturers. In addition to loss of raw materials, it causes inferior half-finished and finished products that are unusable for later processing or are rejected by consumers. 
Packaging errors, including incorrect filling, non-sealed and damaged packaging, and incorrect labeling cause significant food losses within the Belgian food industry. The errors arising during packaging require reworking to ensure standard quality for final products. Given the high cost of reworking, however, products with errors in packaging are usually thrown away. Problems arising from buyer contracts also bring loss to many food processing companies. The buyers normally have the right to reject products if their quality is insufficient (does not meet a certain quality standard) or if the remaining shelf life of products is too short. Moreover, food manufacturers sometimes have to deal with the problem of last-minute cancellation or are faced with sanctions when order volumes are not met.

Additionally, the proportion of food loss varies according to the manufacturer's production scale. Companies with a smaller scale of production ( $<10,000$ tons) suffer higher losses than large scale companies ( $>10,000$ tones), i.e. $2.92 \%$ and $2.84 \%$ total food loss, respectively. Remarkably, human errors are considered the biggest problem in large scale companies (mean $=1.38$ ), while shape/size is the main cause of food loss in small manufacturers (mean = 1.48). However, for both types of food processor, packaging errors are the least important cause of loss (mean $=0.54$ and 0.59 for small and large-scale companies, respectively).

\section{Discussion}

This paper addresses the need to measure food loss at three food processing stages. Despite the global recognition of the issue of food loss within food supply chains, most research in industrialized settings targets post-consumer food waste (Parfitt et al. 2010), while the contribution of the food processing stages is often underestimated (Roels and Van Gijseghem 2011). While previous food waste analysis in Belgium concluded that the majority of food loss during food processing is non-edible (OVAM 2012), our study has shown substantial edible food losses at various processing stages, albeit with varying degrees of quantity.

The findings on the magnitude of food loss in a food manufacturing environment demonstrate a wide variation from one company to another, even within a subsector. Companies producing short shelf-life products (e.g., fruit and vegetables) generate higher losses compared to grain mills. This result supports the claim made by Aung and Chang (2014) and Ali et al. (2017) that perishable food needs better temperature management systems. Our study can add to this argument that appropriate scheduling and planning can help in managing temperature and other parameters to better maintain short shelf-life product and reduce waste.

Further, in our sector-wise analysis, this study reveals that, in terms of quantity, the vegetable and fruit sector contribute to the highest percentages of loss followed by the ready meal sector. Although, in terms of the financial cost of food loss, the chocolate and ready-meal sector ranks joint first. This is in line with an analysis by the FAO (2011), which considers the vegetables (23\% of total cost), meat (21\%), fruits (19\%) and cereals sectors (18\%) as the main contributors to food loss. For meat production, this contribution to the total food wastage cost is likely to be driven by a high unit cost of production. While meat covers $20 \%$ of total economic value, it is only responsible for $4 \%$ of total food wastage. On the other hand, for the cereals sector, a large wastage volume is the main cause of its contribution to total cost. In the case of fruits and vegetables, prices and volumes contribute equally to the total wastage. The main contributors to food wastage volumes are cereals (25\% of total losses), vegetables (24\%), starchy roots (19\%), and fruits (16\%). Altogether, these food crops account for approximately $85 \%$ of total food wastage volumes, and the remaining $15 \%$ comes 
from animal products (FAO 2013). At country level, cereals account for 57\% of the total per capita food supply losses. This is not surprising as they provide $63 \%$ of the total food supply (after losses and waste) of the analyzed food crops (Kummu et al. 2012).

The results of the hotspot analysis and the causes of food loss in each hotspot and product category, provide some interesting insights. Before production (planning/ordering, storage, inventory), three main causes of food loss (wrong order, suboptimal storage and poor inventory management) were identified. In a recent study, Raak et al. (2016) identified similar causes such as resource supply and raw material quality. However, their study ignored the problems with order processing.

Analysis further shows that during the production stage (processing and packaging) one in five companies considers poor transportation, interrupted production, product changes, human errors and product defects as major reasons for food loss. Our study extended the findings of Redlingshofer et al. (2017) by adding product changes (changeover) as a vital cause of food loss. About $13 \%$ of the companies reported substantial losses arising from product changes. Similarly, $8.7 \%$ of the companies linked excessive losses to product defects. This result supports the claim made by Giuseppe et al. (2014), even though their study mainly focuses on the retail sector and not the manufacturing or processing sector.

Our study also confirms previous studies showing that food items are often discarded due to damaged packaging that is linked to improper stock (Cicatiello et al. 2017). Most of the companies expressed that notable sources of (substantial) losses are labelling errors and non-sealed and damaged packaging.

In the after-production stage (inventory, transport and buyer contract), companies experienced food loss due to sub-optimal inventory management (10.9\%) and buyer contracts $(8.5 \%)$. Similarly, Halloran et al. (2014) found that changes in purchase contracts due to obsolete product lines, new product promotions, seasonality or trends can lead to food loss.

Furthermore, the operators/operation managers also revealed that human errors are responsible for most food loss. Human errors are the most frequent cause of food processing loss, occurring in $75 \%$ of participating companies. Specifically, bad handling of food by the employees often originates from lack of knowledge and low levels of training. This is a significant finding which supports an earlier study where Dora et al. (2016) demonstrated that appropriate management training can dramatically reduce human error and prevent losses in food companies.

\subsection{Future research and recommendations}

While it is crucial to determine the extent and causes of food waste at processing level, future research should also assess the effectiveness and feasibility of prevention and reduction measures. Especially for food processing companies, there is still a need to use innovative management systems such as lean manufacturing, Six Sigma and other techniques to prevent food loss (Dora et al. 2013b). While the concept of lean manufacturing has only been applied recently in the food industry to reduce food loss during processing, it has already been shown to be an effective tool that can be successfully implemented in various companies, even in Small and Medium-sized Enterprises (SMEs), and across food sectors and countries (Simons and Zokaei 2005; Lehtinen and Torkko 2005; Dora and Gellynck 2015; Dora et al. 2013b). In addition, as also observed during data collection, the inclusion of food loss in Key Performance Indicators (KPI) as well as the use of appropriate planning and scheduling tools can also help companies to reduce the problem to manageable proportions. While KPIs can improve awareness, targeting and monitoring of food loss (Vlajic et al. 2012), 
holistic approaches to equipment maintenance can avoid breakdowns, small stops, defects or accidents (Tsarouhas 2007; van Kampen and van Donk 2014). Thereby, further research is needed to determine effective strategies to empower operators and create shared responsibility for equipment maintenance and food loss measurement, such as through visualization of food loss objectives (Vlachos 2015).

Furthermore, estimation of the monetary impacts of food losses is crucial for creating awareness among food companies, as they continuously seek cost-efficiency in their production process, including through waste reduction. As our data shows, relative costs of food loss vary substantially (between $£ 0.6$ and $£ 5.9$ per unit), which confirms the recent Waste $\&$ Resources Action Programme study (WRAP 2012). These financial food loss impacts are underestimated, as the true cost goes beyond the monetary consequences of reduced sales by including costs associated with, for example, the production and removal of waste, such as energy and labor (Beretta et al. 2013). As such, the real economic cost of food loss within food companies could be as high as $4 \%$ of the turnover (WRAP 2011, 2012).

There is also a need to better evaluate the interaction between different stakeholders in the food chain (Dreyer et al. 2016). Such a whole chain approach requires the involvement of downstream actors, such as retailers and consumers as the major contributors to food loss and waste in developed countries (Kummu et al. 2012; FAO 2013), but also upstream actors, like farmers.

\section{Conclusions and practical implications}

This study compiled and analyzed the magnitude and hotspots of food losses in 47 foodprocessing companies in Belgium. Two major contributions of this study are: one, while many studies have explored food loss from the demand-side perspective focusing on consumption and end-consumer behaviors, in this paper, we are particularly mapping food loss scenarios in each processing stages. Secondly, we identified major hotspots of food loss with in an industrial processing environment and measured the magnitude of losses across different product categories.

The results regarding hotspots and causes of food loss at different stages of food processing can significantly help food processing companies and practitioners to reduce food loss through investment in (research on) appropriate management techniques. Further, a set of points for attention has been identified, namely that the managers of food producers need to be aware of, different elements of production, planning and control to reduce food loss. In addition, this study has clearly showed, besides sustainable operation factors, how the sector, company size and the nature of products are critical for food loss. The matrix and link between product categories and magnitude of food loss will help companies to devise more customized strategies to reduce specific causes of food loss instead of one-size-fits-all methods. One significant finding is the importance of human error as one of the key causes of food loss. This result will help researchers and food processing companies to design new training programs to teach employees to handle food in an appropriate manner.

Aside from the examined causes of food loss, it is also important to note that the current high rate of food loss is also a result of lack of measurement. Food loss data is often not frequently collected or systematically measured. If one does not know how much or where food loss is occurring in the process, how can one take measures to reduce it? This study helps to lay a framework for companies in terms of where to measure food loss. Finally, given that some of the food loss data in our study was based on expert estimates, it is important 
to interpret the results with caution. Not surprisingly, our study confirms the limited use of proper food loss measurement protocols in many food companies (Aramyan et al. 2007) as well as the unavailability of time-series data, which would allow an accurate identification of trends. This calls for the application of standards for food loss and waste measurement in food companies, similar to the protocol recently development by the World Resources Institute (Hanson et al. 2016).

Open Access This article is distributed under the terms of the Creative Commons Attribution 4.0 International License (http://creativecommons.org/licenses/by/4.0/), which permits unrestricted use, distribution, and reproduction in any medium, provided you give appropriate credit to the original author(s) and the source, provide a link to the Creative Commons license, and indicate if changes were made.

\section{References}

Abass, A. B., Ndunguru, G., Mamiro, P., Alenkhe, B., Mlingi, N., \& Bekunda, M. (2014). Post-harvest food losses in a maize-based farming system of semi-arid savannah area of Tanzania. Journal of Stored Products Research, 57, 49-57.

Akkerman, R., \& van Donk, D. P. (2008). Development and application of a decision support tool for reduction of product losses in the food-processing industry. Journal of Cleaner Production, 16(3), 335-342.

Ali, I., Nagalingam, S., \& Gurd, B. (2017). Building resilience in SMEs of perishable product supply chains: Enablers, barriers and risks. Production Planning \& Control, 28(15), 1236-1250.

Aramyan, L. H., Oude, A. G., Lansink, J. G., Der Vorst, V., \& Van Kooten, O. (2007). Performance measurement in agri-food supply chains: A case study. Supply Chain Management: An International Journal, 12(4), 304-315.

Aschemann-Witzel, J., De Hooge, I. E., Rohm, H., Normann, A., Bossle, M. B., Grønhøj, A., et al. (2017). Key characteristics and success factors of supply chain initiatives tackling consumer-related food waste-A multiple case study. Journal of Cleaner Production, 155, 33-45.

Aulakh, J., \& Regmi, A. (2013). Post-harvest food losses estimation-Development of consistent methodology. Rome: FAO.

Aung, M. M., \& Chang, Y. S. (2014). Temperature management for the quality assurance of a perishable food supply chain. Food Control, 40, 198-207.

BCFN. (2012). Food loss: Causes, impacts and proposal. Parma: Barilla Center for Food and Nutrition.

Beretta, C., Stoessel, F., Baier, U., \& Hellweg, S. (2013). Quantifying food losses and the potential for reduction in Switzerland. Waste Management, 33(3), 764-773.

Betz, A., Buchli, J., Göbel, C., \& Müller, C. (2015). Food waste in the Swiss food service industry-Magnitude and potential for reduction. Waste Management, 35, 218-226.

Bond, M., Meacham, T., Bhunnoo, R., \& Benton, T. G. (2013). Food waste within global food systems. A Global Food Security report. Wiltshire: Global Food Security Programme (GFS).

Buchner, B., Fischler, C., Gustafson, E., Reilly, J., Riccardi, G., Ricordi, C., et al. (2012). Food waste: Causes, impacts and proposals. Parma: Barilla Center for Food \& Nutrition.

Buzby, J. C., Farah-Wells, H., \& Hyman, J. (2014a). The estimated amount, value, and calories of postharvest food losses at the retail and consumer levels in the United States. EIB-121. Washington DC: U.S. Department of Agriculture, Economic Research Service.

Buzby, J. C., Farah-Wells, H., \& Hyman, J. (2014b). The estimated amount, value, and calories of postharvest food losses at the retail and consumer levels in the United States. EIB-121. Washington DC: U.S. Department of Agriculture, Economic Research Service.

Buzby, J. C., \& Hyman, J. (2012). Total and per capita value of food loss in the United States. Food Policy, 37(5), 561-570. https://doi.org/10.1016/j.foodpol.2012.06.002.

Charlebois, S., Creedy, A., \& von Massow, M. (2015). "Back of house"-focused study on food waste in fine dining: The case of Delish restaurants. International Journal of Culture, Tourism and Hospitality Research, 9(3), 278-291.

Childe, S. J. (2011). Case studies in operations management. Production Planning \& Control, 22(2), 107.

Cicatiello, C., Franco, S., Pancino, B., Blasi, E., \& Falasconi, L. (2017). The dark side of retail food waste: Evidences from in-store data. Resources, Conservation and Recycling, 125, 273-281.

Costa, S. J. (2014). Reducing food losses in Sub-Saharan Africa (improving post-harvest management and storage technologies of smallholder farmers)_An 'Action Research' evaluation trial from Uganda and Burkina Faso. Kampala: UN World Food Programme. 
Darlington, R., Staikos, T., \& Rahimifard, S. (2009). Analytical methods for waste minimisation in the convenience food industry. Waste Management, 29(4), 1274-1281. https://doi.org/10.1016/j.wasman.2008. 08.027.

Dora, M., \& Gellynck, X. (2015). Lean Six Sigma Implementation in a food processing SME: A case study. Quality and Reliability Engineering International, 31(7), 1151-1159.

Dora, M., et al. (2012). Adoptability of lean manufacturing among small and medium food processing enterprises. In IIE Annual Conference. Proceedings. Institute of Industrial and Systems Engineers (IISE).

Dora, M., Kumar, M., \& Gellynck, X. (2016). Determinants and barriers to lean implementation in foodprocessing SMEs-A multiple case analysis. Production Planning \& Control, 27(1), 1-23.

Dora, M., Kumar, M., Van Goubergen, D., Molnar, A., \& Gellynck, X. (2013a). Food quality management system: Reviewing assessment strategies and a feasibility study for European food small and mediumsized enterprises. Food Control, 31(2), 607-616.

Dora, M., Van Goubergen, D., De Steur, H., \& Gellynck, X. (2013). Magnitude of "food loss" in Belgian food processing industry: Results from multiple case studies. In IIE Annual Conference. Proceedings, San Juan, Puerto Rico.

Dora, M., Van Goubergen, D., Kumar, M., Molnar, A., \& Gellynck, X. (2013c). Application of lean practices in small and medium-sized food enterprises. British Food Journal, 116(1), 125-141.

Dreyer, H. C., Strandhagen, J. O., Hvolby, H.-H., Romsdal, A., \& Alfnes, E. (2016). Supply chain strategies for speciality foods: A Norwegian case study. Production Planning \& Control, 27(11), 878-893.

EC. (2010). Preparatory study on food loss across EU 27. Technical report. Brussels: European Commission.

Eisenhardt, K. M. (1989). Building theories from case study research. Academy of Management Review, 14(4), 532-550.

Engström, R., \& Carlsson-Kanyama, A. (2004). Food losses in food service institutions Examples from Sweden. Food Policy, 29(3), 203-213. https://doi.org/10.1016/j.foodpol.2004.03.004.

Eriksson, M., Strid, I., \& Hansson, P.-A. (2012). Food losses in six Swedish retail stores: Wastage of fruit and vegetables in relation to quantities delivered. Resources, Conservation and Recycling, 68, 14-20. https:// doi.org/10.1016/j.resconrec.2012.08.001.

European Court of Auditors. (2016). Combating Food Waste: An opportunity for the EU to improve the resource-efficiency of the food supply chain. Luxembourg: European Union.

Evans, D. (2011). Blaming the consumer-once again: The social and material contexts of everyday food waste practices in some English households. Critical Public Health, 21(4), 429-440.

FAO. (2011). Global food losses and food waste - Extent, causes and prevention. Rome: Food and Agriculture Organization of the United Nations.

FAO. (2013). Food wastage footprint: Impacts on natural resources. Rome: FAO.

Fehr, M., Calçado, M. D. R., \& Romão, D. C. (2002). The basis of a policy for minimizing and recycling food waste. Environmental Science \& Policy, 5(3), 247-253. https://doi.org/10.1016/S1462-9011(02)000369.

Flapper, S. D. P., Fransoo, J. C., Broekmeulen, R. A. C. M., \& Inderfurth, K. (2002). Planning and control of rework in the process industries: A review. Production Planning \& Control, 13(1), 26-34.

Food, and Agriculture Organization of the United Nations. (2013). Food wastage footprint: Impacts on natural resources: Summary report. Rome: FAO.

Food Drink Europe. (2014). Preventing food wastage in the food and drink sector. Europe's food and drink manufacturers take action to prevent food wastage. Brussels: Food Drink Europe.

Fox, T., \& Fimeche, C. (2013). Global food: Waste not, want not. London: Institution of Mechanical Engineers.

Gillham, B. (2000). Case study research methods. London, New York: Bloomsbury Publishing.

Girotto, F., Alibardi, L., \& Cossu, R. (2015). Food waste generation and industrial uses: A review. Waste Management, 45, 32-41.

Giuseppe, A., Mario, E., \& Cinzia, M. (2014). Economic benefits from food recovery at the retail stage: An application to Italian food chains. Waste Management, 34(7), 1306-1316.

Gummesson, E. (2000). Qualitative methods in management research. CA Sage: Thousand Oaks.

Gustavsson, J., Cederberg, C., Sonesson, U., Van Otterdijk, R., \& Meybeck, A. (2011). Global food losses and food waste. Rome: Food and Agriculture Organization of the United Nations (FAO).

Halloran, A., Clement, J., Kornum, N., Bucatariu, C., \& Magid, J. (2014). Addressing food waste reduction in Denmark. Food Policy, 49, 294-301.

Hanson, C., Lipinski, B., Robertson, K., Dias, D., Gavilan, I., Grévarath, P., et al. (2016). Food loss and waste accounting and reporting standard. WRI, Nestlé, CGF, FAO, EU-funded FUSIONS project, UNEP, WRAP, WBCSD, NRI. URL.

Harder, R., Kalmykova, Y., Morrison, G. M., Feng, F., Mangold, M., \& Dahlén, L. (2014). Quantification of goods purchases and waste generation at the level of individual households. Journal of Industrial Ecology, 18(2), 227-241. 
Ivert, L. K., Dukovska-Popovska, I., Kaipia, R., Fredriksson, A., Dreyer, H. C., Johansson, M. I., et al. (2015). Sales and operations planning: Responding to the needs of industrial food producers. Production Planning \& Control, 26(4), 280-295.

Jick, T. D. (1979). Mixing qualitative and quantitative methods: Triangulation in action. Administrative Science Quarterly, 24(4), 602-611.

Kaipia, R., Dukovska-Popovska, I., \& Loikkanen, L. (2013). Creating sustainable fresh food supply chains through waste reduction. International journal of physical distribution \& logistics management, 43(3), $262-276$.

Kantor, L. S., Lipton, K., Manchester, A., \& Oliveira, V. (1997). Estimating and addressing America's food losses. Food review, 20(1), 2-12.

Kennedy, I., Plunkett, A., \& Haider, J. (2013). Implementation of lean principles in a food manufacturing company. In Advances in sustainable and competitive manufacturing systems (pp. 1579-1990). Springer.

Kiil, K., Dreyer, H. C., Hvolby, H.-H., \& Chabada, L. (2017). Sustainable food supply chains: The impact of automatic replenishment in grocery stores. Production Planning \& Control, 29, 106-116.

Kummu, M., De Moel, H., Porkka, M., Siebert, S., Varis, O., \& Ward, P. J. (2012). Lost food, wasted resources: Global food supply chain losses and their impacts on freshwater, cropland, and fertiliser use. Science of the Total Environment, 438, 477-489.

Lamb, G., \& Fountain, L. (2010). An investigation into food loss management. Waste in Action 2010. UK: Waste in Action.

Lebersorger, S., \& Schneider, F. (2011). Discussion on the methodology for determining food waste in household waste composition studies. Waste Management, 31(9-10), 1924-1933. https://doi.org/10.1016/j. wasman.2011.05.023.

Lehtinen, U., \& Torkko, M. (2005). The Lean concept in the food industry: A case study of a contract manufacturer. Journal of Food Distribution Research, 36(3), 57.

Lipinski, B., Hanson, C., Lomax, J., Kitinoja, L., Waite, R., \& Searchinger, T. (2013). Reducing food loss and waste. Working Paper. Washington: World Resources Institute.

Lundqvist, J., de Fraiture, C., \& Molden, D. (2008). Saving water: From field to fork: Curbing losses and wastage in the food chain. Stockholm: Stockholm International Water Institute Stockholm.

Martindale, W. (2010). Waste: Uncovering the global food scandal. New York: WW Norton \& Company.

Mena, C., Adenso-Diaz, B., \& Yurt, O. (2011). The causes of food waste in the supplier-retailer interface: Evidences from the UK and Spain. Resources, Conservation and Recycling, 55(6), 648-658.

Munesue, Y., Masui, T., \& Fushima, T. (2015). The effects of reducing food losses and food waste on global food insecurity, natural resources, and greenhouse gas emissions. Environmental Economics and Policy Studies, 17(1), 43-77.

Nahman, A., de Lange, W., Oelofse, S., \& Godfrey, L. (2012). The costs of household food waste in South Africa. Waste Management, 32(11), 2147-2153. https://doi.org/10.1016/j.wasman.2012.04.012.

Oelofse, S. H., \& Nahman, A. (2013). Estimating the magnitude of food waste generated in South Africa. Waste Management and Research, 31(1), 80-86.

OVAM. (2012). Voedselverlies in ketenperspectief. Mechelen: OVAM.

Papargyropoulou, E., Lozano, R., Steinberger, J. K., Wright, N., \& bin Ujang, Z. (2014). The food waste hierarchy as a framework for the management of food surplus and food waste. Journal of Cleaner Production, 76, 106-115.

Parfitt, J., Barthel, M., \& Macnaughton, S. (2010). Food waste within food supply chains: Quantification and potential for change to 2050. Philosophical Transactions of the Royal Society of London B: Biological Sciences, 365(1554), 3065-3081.

Raak, N., Symmank, C., Zahn, S., Aschemann-Witzel, J., \& Rohm, H. (2016). Processing-and product-related causes for food waste and implications for the food supply chain. Waste Management, 61, 461-472.

Redlingshofer, B., Coudurier, B., \& Georget, M. (2017). Quantifying food loss during primary production and processing in France. Journal of Cleaner Production, 164, 703-714.

Redlingshöfer, B., \& Soyeux, A. (2012). Food losses and wastage as a sustainability indicator of food and farming systems. Paper presented at the Proceedings of the Producing and Reproducing Farming Systems: New Modes of Organisation for Sustainable Food Systems of Tomorrow, 10th European IFSA Symposium, Aarhus, Denmark.

Reich, A. H., \& Foley, J. A. (2014). Food loss and waste in the US: The science behind the supply chain. Institute on the Environment, University of Minnesota. Retrieved 2/22/2015 from.

Richter, B., \& Bokelmann, W. (2016). Approaches of the German food industry for addressing the issue of food losses. Waste Management, 48, 423-429.

Roels, K., \& Van Gijseghem, D. (2011). Verlies en verspilling in de voedselketen. Departement Landbouw en Visserij, afdeling Monitoring en Studie. 
Rutten, M. M., \& Mhlanga, N. (2015). Potential impacts on sub-Saharan Africa of reducing food loss and waste in the European Union. Rome: FAO.

SAVE FOOD. (2016). Global initiative on food losses and waste reduction. In Key facts on food loss and waste you should know. Rome: FAO.

Segrè, A., Falasconi, L., Politano, A., \& Vittuari, M. (2014). Background paper on the economics of food loss and waste. Working paper. Rome: FAO.

Sheahan, M., \& Barrett, C. B. (2017). Food loss and waste in Sub-Saharan Africa: A critical review. Food Policy, 70, 1-12.

Shukla, M., \& Jharkharia, S. (2013). Agri-fresh produce supply chain management: A state-of-the-art literature review. International Journal of Operations \& Production Management, 33(2), 114-158.

Simons, D., \& Zokaei, K. (2005). Application of lean paradigm in red meat processing. British Food Journal, 107(4), 192-211.

Stancu, V., Haugaard, P., \& Lähteenmäki, L. (2016). Determinants of consumer food waste behaviour: Two routes to food waste. Appetite, 96, 7-17.

Stenmarck, Å., Jensen, C., Quested, T., Moates, G., Buksti, M., Cseh, B., et al. (2016). Estimates of European food waste levels: IVL. Swedish Environmental Research Institute.

Tadei, R., Trubian, M., Avendano, J. L., Della Croce, F., \& Menga, G. (1995). Aggregate planning and scheduling in the food industry: A case study. European Journal of Operational Research, 87(3), 564-573.

Taleghani, M. (2010). Key factors for implementing the lean manufacturing system. Journal of American science, 6(7), 287-291.

Tsarouhas, P. (2007). Implementation of total productive maintenance in food industry: A case study. Journal of Quality in Maintenance Engineering, 13(1), 5-18.

Van Goubergen, D., Dora, M., Molnar, A., Gellynck, X., \& Kumar, M. (2011). Lean application among European food SMEs: Findings from empirical research. In IIE Annual Conference. Proceedings (p. 1). Institute of Industrial and Systems Engineers (IISE).

van Kampen, T. J., \& van Donk, D. P. (2014). When is it time to revise your SKU classification: Setting and resetting the decoupling point in a dairy company. Production Planning \& Control, 25(16), 1338-1350.

Vergamini, D., Cuming, D., \& Viaggi, D. (2015). The integrated management of food processing waste: the use of the full cost method for planning and pricing Mediterranean citrus by-products. International Food and Agribusiness Management Review, 18(2), 153.

Verghese, K., Lewis, H., Lockrey, S., \& Williams, H. (2015). Packaging's role in minimizing food loss and waste across the supply chain. Packaging Technology and Science, 28(7), 603-620.

Vlachos, I. (2015). Applying lean thinking in the food supply chains: A case study. Production Planning \& Control, 26(16), 1351-1367.

Vlajic, J. V., Van der Vorst, J. G., \& Haijema, R. (2012). A framework for designing robust food supply chains. International Journal of Production Economics, 137(1), 176-189.

Wezel, V., Wout, D. P., Donk, V., \& Gaalman, G. (2006). The planning flexibility bottleneck in food processing industries. Journal of Operations Management, 24(3), 287-300.

Wille, D. (2015). Food loss and packaging. Mechelen: OVAM.

WRAP. (2011). Fruit and vegetable resource maps. Banbury: WRAP.

WRAP. (2012). Estimate of waste in the food and drink supply chain. Banbury: WRAP.

Yin, R. K. (2013). Case study research: Design and methods. Thousand Oaks: Sage Publications.

Publisher's Note Springer Nature remains neutral with regard to jurisdictional claims in published maps and institutional affiliations. 